\title{
Combined Clozapine and Electroconvulsive Therapy in a Japanese Schizophrenia Patient: A Case Report
}

\author{
Yuta Yoshino', Yuki Ozaki', Koichiro Kawasoe', Shinichiro Ochi', Takanori Niiya1, Naomi Sonobe', Teruhisa Matsumoto', \\ Shu-ichi Ueno \\ ${ }^{1}$ Department of Neuropsychiatry, Ehime University Graduate School of Medicine, ${ }^{2}$ Department of Postgraduate Clinical Training Center, \\ Ehime University Hospital, Shitsukawa, Japan
}

\begin{abstract}
Clozapine is well-known for successful use in schizophrenic patients treatment resistant to other antipsychotics. However, even with clozapine, $25 \%$ of schizophrenic patients are not in remission. Recently, as adjunctive treatment with clozapine, electroconvulsive therapy has been reported to be an effective and safe adjunctive treatment. We report a Japanese schizophrenic woman who was not in remission with clozapine alone but with both clozapine and electroconvulsive therapy.
\end{abstract}

KEY WORDS: Schizophrenia; Clozapine; Electroconvulsive therapy; Lithium.

\section{INTRODUCTION}

Clozapine (CLZ) is a well-known antipsychotic used for schizophrenic patients treatment resistant to at least two conventional antipsychotics. ${ }^{1)}$ However, even with CLZ, $25 \%$ of schizophrenic patients are not in remission ${ }^{2)}$ and require adjunctive therapy. For this purpose, lamotrigine augmentation is sometimes effective. ${ }^{3)}$ Recently, combined CLZ and electroconvulsive therapy (ECT) has been reported to be effective and safe. ${ }^{4)}$ Here we report a Japanese schizophrenic woman who was not in remission only with CLZ treatment, but remitted with combined CLZ and ECT for the residual symptoms of psychomotor excitement and mood instability.

\section{CASE}

The patient was a 37-year-old Japanese woman. She presented with auditory hallucinations and delusions at the age of 26 and was diagnosed as having schizophrenia. She took several antipsychotics but no medicines were effective for the first decade of her illness. She was referred to our university hospital at the age of 35 for further treat-

\footnotetext{
Received: February 11, 2014 / Revised: February 24, 2014

Accepted: February 25, 2014

Address for correspondence: Yuta Yoshino, MD

Department of Neuropsychiatry, Ehime University Graduate School

of Medicine, Shitsukawa, Toon, Ehime 791-0295, Japan

Tel: +81-89-960-5315, Fax: +81-89-960-5317

E-mail:whisperoftheheart2@yahoo.co.jp
}

ment and received in-patient care. In this first hospitalization, she was led to remission with $20 \mathrm{mg}$ /day of olanzapine, $3 \mathrm{mg} /$ day of risperidone, and $200 \mathrm{mg}$ /day of carbamazepine. After discharge following 6 months of hospitalization, she was stable for 6 months, but stopped taking her antipsychotics because of insufficient insight and entered our hospital again because she broke the windows of a neighbor's house under the influence of erotomanic delusions. During her second hospitalization, she took $24 \mathrm{mg}$ /day of blonanserin (an antipsychotic used in Japan and Korea, where $24 \mathrm{mg}$ /day is the maximum dose) but ultimately neither olanzapine nor blonanserin were sufficiently effective. Lithium is reported to work as a neutoropenia prophylactic with CLZ-induced neutrophil count dropping. ${ }^{5)}$ We prescribed her because of neutropenia. We concluded that she had treatment-resistant schizophrenia and started CLZ treatment according to the Clozaril Patient Monitoring Service at the 157th day of her in-patient stay. CLZ was increased up to $600 \mathrm{mg} /$ day, but she developed a prolonged QT interval (QTc: $0.454 \mathrm{~s}$, normal range; $0.36-0.44 \mathrm{~s}$ ) one week after the increase to 600 $\mathrm{mg} /$ day. We decreased CLZ to $500 \mathrm{mg} /$ day. Her prolonged QT interval improved (QTc: $0.433 \mathrm{~s}$ ) and we maintained that CLZ dose. She was monitored with electrocardiogram every 2 weeks. Even after combination therapy with ECT, her QT interval did not change at all. Auditory hallucinations and delusions were improved but she presented symptoms of psychomotor excitement and mood in-

(a) This is an Open-Access article distributed under the terms of the Creative Commons Attribution Non-Commercial License (http://creativecommons.org/licenses/by-nc/3.0) which permits unrestricted non-commercial use, distribution, and reproduction in any medium, provided the original work is properly cited. 
stability a week later when she was released from isolation in a single room and allowed to move freely in the psychiatric ward. It is reported that some CLZ-resistant patients recovered with lamotrigine augmentation. ${ }^{3)}$ We selected lamotrigine as an augmentation therapy at first. However, even with lamotrigine augmentation at $200 \mathrm{mg} /$ day, her symptoms of psychomotor excitement and mood instability were not improved.

We prescribed yokukansan (Japanese herbal medicine; sometimes works for improving psychiatric symptoms) $7.5 \mathrm{~g}$ /day to improve mood stability. ${ }^{6}$ The effect was mild in degree and her symptoms remained largely unchanged.

We subsequently selected a trial of combined CLZ and ECT therapy. She had been taking $500 \mathrm{mg}$ /day of CLZ for 20 weeks before the initiation of ECT. Anesthesia was induced with propofol $(2.0 \mathrm{mg} / \mathrm{kg}$ for the first treatment, $1.0-1.5 \mathrm{mg} / \mathrm{kg}$ for all subsequent treatments) and succinylcholine (1.0-1.2 mg/kg), and ECT was administered with the somatic Thymatron ${ }^{\mathrm{R}}$ ECT System IV (Somatics LLC, Lake Bluff, IL, USA). Treatment was started with bilateral electrode placement. She was asked about side effects after every ECT. ECT was given twice or three times per week and ten administrations of ECT were given in each course of treatment.

After one course, her symptoms of psychomotor excitement and mood instability improved. Only anterograde amnesia was present as an adverse effect but this disappeared gradually within a few hours. She did not have to stay in her own room and her mood and behaviors were subsequently stable for at least 4 weeks. She presented mild degrees of tension and hostility. Continuation (maintenance) ECT was then done twice every 4 weeks and there were no significant ill effects. Maintenance ECT

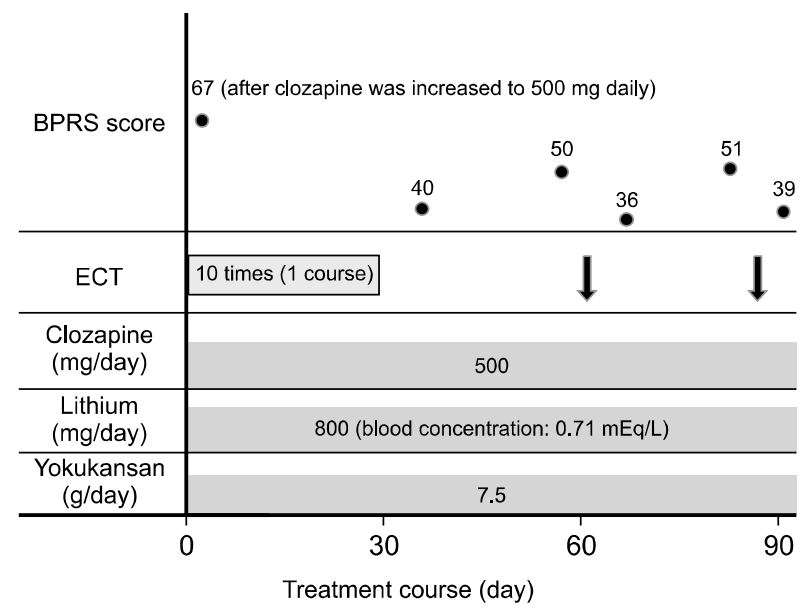

Fig. 1. Treatment course of our case. BPRS, Brief Psychiatric Rating Scale; ECT, electroconvulsive therapy. will be continued once a month indefinitely while her symptoms are observed. We evaluated her psychiatric symptoms with the Brief Psychiatric Rating Scale (BPRS) (Fig. 1). Before CLZ treatment was started her BPRS score was 81 , was reduced to 67 with $500 \mathrm{mg}$ /day CLZ, and further reduced to 40 after one course of ECT.

\section{DISCUSSION}

CLZ is a unique antipsychotic in several respects. Its pharmacological mechanisms include dopamine type 4 receptor blocking and/or N-methyl-D-aspartate receptor activation through glutamate release in addition to binding activity to the dopamine type 2 receptor, but its antipsychotic mechanism is still unknown in detail. ${ }^{7,8)}$ On serum CLZ levels in blood, Matsuda et al. ${ }^{9)}$ reported that they were significantly lower in Asian patients than in Caucasians. Side effects of CLZ are also unique. Abnormal electroencephalogram (EEG) changes and neutropenia or agranulocytosis are well-known side effects. ${ }^{9,10)}$ In particular, agranulocytosis occurs among Asian patients more frequently than among Caucasians. ${ }^{9)}$ The effectiveness and side effects of CLZ treatment may be different among different racial groups. In this case, we decreased CLZ from $600 \mathrm{mg}$ to $500 \mathrm{mg}$ because of the QT prolongation without change in psychiatric symptoms.

Recently, there have been several reports about combined CLZ and ECT therapy. ${ }^{411)}$ Generally, combined CLZ and ECT for schizophrenia patients are known to be more effective for positive symptoms than for negative symptoms. ${ }^{4)}$ In this case, we administered ECT after adequate CLZ treatment and the symptoms of mood instability and hostility in this patient were improved. Because combined CLZ and ECT for Asian schizophrenia patients have been rarely reported, our experience suggests that treatment-resistant patients may react well to ECT after CLZ treatment.

There are some reports about risk of excessive cognitive disturbance, prolonged apnea, and spontaneous seizures when applying ECT in patients already having taken lithium. However, others reported that there were no correlations between them. ${ }^{12,13)}$ In this case, we monitored vital signs and cognitive disturbances after each ECT, but those side effects were not appeared.

There are two limitations. Firstly, she did not receive ECT monotherapy, so we could not compare ECT monotherapy to combined CLZ and ECT. However, any antipsychotics other than CLZ did not work for her mental problems at all, and only with both $500 \mathrm{mg}$ of CLZ and 
ECT made her recover and discharge from the hospital. Secondly, we followed this patient for only 12 weeks after the initial course of ECT. Havaki-Kontaxaki et al. ${ }^{4)}$ reported that combined CLZ and ECT for schizophrenia patients was effective but that $45.4 \%$ of patients relapsed and substantial improvement persisted beyond 4 months in only $22.7 \%$, implying the need for careful follow up.

There are few reports of combined CLZ and ECT in Asian schizophrenia patients. In conclusion, experience is needed with additional cases from several different Asian racial backgrounds to accurately evaluate the effectiveness of combined CLZ and ECT.

\section{REFERENCES}

1. Kane J, Honigfeld G, Singer J, Meltzer H. Clozapine for the treatment-resistant schizophrenic. A double-blind comparison with chlorpromazine. Arch Gen Psychiatry 1988; 45:789-796.

2. Wahlbeck K, Cheine M, Essali A, Adams C. Evidence of clozapine's effectiveness in schizophrenia: a systematic review and meta-analysis of randomized trials. Am J Psychiatry 1999;156:990-999.

3. Zoccali R, Muscatello MR, Bruno A, Cambria R, Micò U, Spina $\mathrm{E}$, et al. The effect of lamotrigine augmentation of clozapine in a sample of treatment-resistant schizophrenic patients: a double-blind, placebo-controlled study. Schizophr Res 2007:93:109-116.

4. Havaki-Kontaxaki BJ, Ferentinos PP, Kontaxakis VP, Paplos KG, Soldatos CR. Concurrent administration of clozapine and electroconvulsive therapy in clozapineresistant schizophrenia. Clin Neuropharmacol 2006;29:5256.
5. Blier P, Slater S, Measham T, Koch M, Wiviott G. Lithium and clozapine-induced neutropenia/agranulocytosis. Int Clin Psychopharmacol 1998;13:137-140.

6. Miyaoka T, Furuya M, Yasuda H, Hayashida M, Nishida A, Inagaki $\mathrm{T}$, et al. Yi-gan san as adjunctive therapy for treatment-resistant schizophrenia: an open-label study. Clin Neuropharmacol 2009;32:6-9.

7. Hwang R, Tiwari AK, Zai CC, Felsky D, Remington E, Wallace $\mathrm{T}$, et al. Dopamine D4 and D5 receptor gene variant effects on clozapine response in schizophrenia: replication and exploration. Prog Neuropsychopharmacol Biol Psychiatry 2012;37:62-75.

8. Melone M, Vitellaro-Zuccarello L, Vallejo-Illarramendi A, Pérez-Samartin A, Matute C, Cozzi A, et al. The expression of glutamate transporter GLT-1 in the rat cerebral cortex is down-regulated by the antipsychotic drug clozapine. Mol Psychiatry 2001;6:380-386.

9. Matsuda KT, Cho MC, Lin KM, Smith MW, Young AS, Adams JA. Clozapine dosage, serum levels, efficacy, and side-effect profiles: a comparison of Korean-American and Caucasian patients. Psychopharmacol Bull 1996;32:253257.

10. Chung SJ, Jeong SH, Ahn YM, Kang UG, Koo YJ, Ha JH, et al. A retrospective study of clozapine and electroencephalographic abnormalities in schizophrenic patients. Prog Neuropsychopharmacol Biol Psychiatry 2002;26:139144.

11. Masoudzadeh A, Khalilian AR. Comparative study of clozapine, electroshock and the combination of ECT with clozapine in treatment-resistant schizophrenic patients. Pak J Biol Sci 2007;10:4287-4290.

12. Dolenc TJ, Rasmussen KG. The safety of electroconvulsive therapy and lithium in combination: a case series and review of the literature. J ECT 2005;21:165-170.

13. Mukherjee S. Combined ECT and lithium therapy. Convuls Ther 1993;9:274-284. 